\title{
DEVIR-LOBO NA INFÂNCIA: KIPLING E SUA MATILHA
}

\author{
Deniz Alcione NICOLAY \\ Programa de Pós-Graduação em Educação/UFRGS \\ deniznicolay@hotmail.com
}

\begin{abstract}
RESUMO: O propósito deste ensaio é o de reinterpretar a noção de desejo na infância, tal como ensinado e categorizado pelas contribuições psicanalíticas. Nesse sentido, procura refutar a triangulação edipiana, como única forma de entender a produção inconsciente, já que está inibe o desejo nas malhas do pensamento representacional. Por isso, entende a infância como uma verdadeira máquina desejante e pensá-la, dessa forma, significa partilhar das concepções desenvolvidas por Deleuze e Guattari no seu Anti-Édipo. Entretanto, é apenas nos Mil Platôs que as pistas para esse ensaio são delineadas. Apropriando-se dos conceitos de devir-animal e de matilha, ele realiza, à luz da Filosofia da Diferença, aproximações com a obra literária de Rudyard Kipling. De maneira muito especial, o Livro da Selva é o exemplo mais ilustre da produção desejante na infância. Assim, verificase a inversão da lógica freudiana: do sujeito que deseja algo, por devires pré-individuais, multiplicidades, espalhadas pela floresta como a matilha de lobos.
\end{abstract}

Palavras-chave: Desejo. Infância. Devir-lobo. Matilha

Abstract: This essay is an attempt to interpreter the notion of wish to childhood, such as teached and categoryed for psychoanalysis contributions. In this sense, search to refute the edipian triangle, as a only form of to understand the unconscious production, already this the wish them mesh of the representation thought. Out of, to understand the childhood as one truth desirable machine and to think she, like this, signify to share in the conceptions developeds for Deleuze and Guattari on the his AntiÉdipo. However, is only them Mil Platôs that traces for this essay are outlineds. Take possession of the concepts of becoming-animal and rabble, it to achieve, by the light of Philosophy of the Difference, approximations with the literary work of the Rudyard Kipling. Of way very special, the Book of Jungle is the example most illustrious of the desirable production to childhood. Like this, to verify the inverse of the freudiana logic: of the subject, that to long for something becomings precedeindividuais, multiples, to scatter for the florest as the rabble in the wolfs.

Keywords: Wish. Childhood. Becoming-wolf. Rabble

O desejo não é apenas o produto da energia libidinal associada às funções orgânicas de prazer ou desprazer, nem a vontade obscurecida pelo objeto desejado, tampouco um mecanismo de representação artificial, que atribui a trindade psicanalítica (eu-papai-mamãe) seu código prescrito de realização. Aliás, o desejo, em si mesmo, não tem por função realizar absolutamente nada daquilo que entendemos por satisfação pessoal, uma vez que a própria atividade consumatória em relação ao objeto desejado significa, em certo sentido, dispêndio e frustração da potência instintiva aplicada sobre a matéria. A sensação de nunca chegar a lugar algum precede aos instantes de dissolução, de esvaziamento, de liberação da culpa reprimida, porque aprendemos a acreditar que no tribunal do juízo de Deus nossa única segurança é sua sombra. Mesmo que essa sombra seja a projeção distorcida das atividades sublimatórias do 
desejo, naquilo que concebemos como vontade criativa. É do mesmo porão imundo, que surge o traço expressivo capaz de criar as manifestações estéticas do mundo cultural; entretanto, quando a sujeira acumula, formando blocos calcificados de recalque, costumamos penalizar o corpo por sua incapacidade de operar com o desejo, de modo que o neurótico, o psicótico e o esquizofrênico transitam em nossa casa sem nenhum medo do escuro. Talvez, quando o corpo assim procede, tenhamos que aprender a conter a sombra histriônica que insiste no sádico jogo de inverter os papéis, fazendo-nos passar de caçador à caça principal. Talvez tenhamos que aprender, por conta própria, a limpar a sujeira da casa, deixá-la limpa para um novo investimento, sem ressentimentos ou encargos de consciência. Mas, antes de tudo, talvez tenhamos que aprender a conter e extirpar da própria consciência a sombra de Deus. Porém, sobre isso a psicanálise não nos ensinou, já que seu "segredinho sujo" acaba sempre levando ao mesmo problema, o qual opta por reprimir a fantástica produção do desejo e, com isso, sufoca a mutabilidade anárquica que atravessa nossos corpos em fluxos de energia, em devires esquizos: de nomes, palavras, coisas.

Aprendemos a ter medo de desejar, porque isso significa recriar as terríveis sombras do passado. Ninguém gosta de remexer na imundície da civilização, para resgatar do lodo a própria identidade, sem ao menos sujar as mãos com as mais obscenas recordações de papaimamãe-e-eu. Por isso, o desejo, ao invés de provocar a alucinada produção desejante, o cio carnal e esquizofrênico das máquinas desejantes, a divina energia que percorre as profundezas da natureza inconsciente, é reduzido apenas

a uma forma trinitária e edipiana de justificação da sexualidade latente. Na sua genealogia cristã é a própria dor da culpa pelo pecado original, o receio do castigo divino aplicado sobre o corpo pecador, o sentimento de falta pela morte do Cristo, o ressentimento judaico-cristão contra toda forma de poder que se impõe, porque naturalmente mais forte que seu oponente. O desejo tornou-se coisa de fracos, uma vez que a grande questão oscila exatamente em como reduzi-lo, torná-lo insignificante frente à produção gregária da esfera social no mundo do trabalho. Para, com isso, minimizar o potencial destrutivo da besta-fera e canalizá-lo na força do trabalho braçal tornando-o, antes de tudo, um animal familiar que brinca com suas crianças no domingo. Mas do quê brincam suas crianças? Será que a tragédia edipiana repetir-se-á nos filhos de seus filhos, como um ciclo vicioso? Será que o desejo infantil é apenas a falta recalcada, que provoca uma produção reativa de seu corpo sem órgãos?

São os desvios do desejo, assumidos pela economia capitalista, assim como a domesticação das forças fluídas do indivíduo, praticada pela psicanálise, que nos provocam a 
vontade de pensar a infância como uma verdadeira máquina desejante. Ora, a infância como máquina desejante opera a libertação do mito Edípico pela própria morte do papai e da mamãe simbólicos e, com isso, constitui-se numa forma humana in natura, na medida em que expulsa os velhos fantasmas e rompe com a bagagem hereditária dos filhos de Deus. Ela se assemelha ao esquizofrênico, que embaralha todos os códigos para provocar uma multiplicação indefinida de palavras, genealogias, acontecimentos, linguagens, fugindo sempre de toda e qualquer tentativa de enquadramento psíquico, inclusive, da nomenclatura gramatical que lhe insiste em designar o verbo na primeira pessoa. Não existe um "Eu" na infância como máquina desejante, mas apenas blocos de intensidades, que na força persuasiva do tempo recriam, a cada instante, a sensação de estados vividos, porém infinitos. É a própria produção da produção, uma máquina acoplada a outra e, assim, indefinidamente uma ligação que, ao mesmo tempo, é durável por seus movimentos maquínicos, mas volúvel pela sua ação gerativa. Pois as máquinas desejantes mudam de forma, conforme o acoplamento que recebem, independente se a composição cooperativa apresenta afinidade de interesses; aliás, é exatamente por operações disjuntivas, dessemelhantes, dissociativas que a produção desejante parece exercer sua mais perfeita sincronia com o movimento maquínico. Desse modo, não devemos nos esquecer de que: “As máquinas desejantes só andam desarranjadas, desarranjando-se sem cessar." (Deleuze e Guattari, 1976, p.23.), como se fossem as peças de um quebra-cabeça que partem sempre de um lugar diferente.

Devemos lembrar ainda, que a infância como máquina desejante, é um acerto de contas com a noção de corpo sem órgãos, uma vez que a psicanálise entendeu apenas a face destrutiva de tal conceito, aproximando-o do instinto de morte freudiano. Associado ao esquizofrênico, o corpo sem órgãos é sua própria pulsão produtiva manifesta no campo social, uma espécie de espaço ilimitado de circulação de devires, de deslocamentos constantes entre estados de coisas, onde a intensidade apropriativa da força utilizada é que determina a forma da matéria, bem como a tensão do instante, seguindo o círculo do Eterno Retorno. Entretanto, o corpo sem órgãos não pode ser entendido apenas como uma projeção do corpo pleno da terra, uma vez que não segue nenhum modelo pré-estabelecido, muito menos a disposição de um socius de produção econômica e, portanto, nada cria voluntariamente sem receber o preenchimento da produção desejante em todos os seus mínimos interstícios. Ele opera por desterritorializações constantes, por abalos de pensamento, mas necessita de uma conexão vital com o corpo esfarrapado do esquizofrênico, ainda que não tenha este como a última morada. Trata-se, assim, de liberar o desejo infantil das amarras sociais impostas pelas máquinas técnicas de domesticação e de produção do medo, como um pássaro que aprende a 
voar, porque simplesmente não encontra mais nenhum ponto de sustentação. Na sua frente, apenas o ar puro para respirar e o desejo de voar.

A infância como máquina desejante não acredita mais em nenhuma promessa de salvação do gênero humano pela via religiosa. Além disso, Deus é uma força que deve ser superada em proveito de algo mais expressivo, de algo manifesto em sua concretude positiva e no seu poder de recriar a produção desejante. Nada de escuta como terapia para liberação do ego individual, como se o corpo sem órgãos fosse o responsável pela produção negativa do desejo e, assim, recebesse rótulos e clichês psicanalíticos. O desejo é a produção livre da capacidade humana de produzir, criar e agir e, portanto, uma das nossas energias vitais. Por isso, temos que afirmar de que uma criança não brinca apenas de papai e mamãe, mas de outros e outros brinquedos conforme sua vontade assim o determinar. Talvez Freud tenha entendido muito pouco do desejo infantil, porque insistia numa mesma explicação para todos os fenômenos que se lhe apresentavam, sem nenhum escrúpulo pela repetição da mesmidade. Talvez tenhamos que procurar outro conto infantil, distante da tragédia edípica, e que ilustre a potência originária do desejo infantil, sem nenhuma vestimenta e ao natural. Encontramos uma pista quando Deleuze e Guattari afirmam que: "Kipling compreendia melhor do que Freud o apelo dos lobos, seu sentido libidinal;(...)" (1995, p.44). Então, transformamos a infância da máquina desejante em devir-lobo para apreciar o investimento do desejo num autêntico conto infantil, daqueles que contamos para crianças que esperam a hora de dormir.

Trata-se do Livro da Selva de Kipling, do conto intitulado “Os irmãos de Mogli”, onde o cenário transcorre nas vastas florestas indianas. O menino Mogli, perdido por seus pais numa caçada pela floresta, acaba encontrando uma caverna de lobos onde encontra abrigo. A família de lobos termina adotando o menino e criando-o como um verdadeiro membro da matilha. Mas, antes disso, Mogli teve de ser aceito e reconhecido como membro do povo livre. Ele conquista a confiança do velho lobo Akela, líder do bando, porém, o desprezo do tigre Shere Khan, que promete devorá-lo a qualquer momento. Outros dois amigos tomam partido na proteção do jovem menino-lobo, Baloo (o urso) e Baguera (a pantera). O enfrentamento entre Mogli e Shere Khan é esperado por todo o povo da floresta, de modo que a trama provoca o leitor para descobrir o resultado final do embate. Alguns lobos tomam partido de um, outros do outro, mas todos sabem que o vencedor do duelo assumirá a liderança do povo livre e o controle dos territórios de caça. Como o velho lobo, Akela, estivesse muito doente sua liderança é colocada em cheque pelos membros mais novos do grupo, que apoiavam o tigre. Sem o grande líder, Mogli, terá que se defender contra os ataques inimigos. Instruído por Baguera, vai até a cidade dos homens e traz uma centelha da 
flor vermelha (fogo), o que provoca um terrível alarido entre os lobos, pois o menino queima vários comparsas, inclusive, Shere Kan. Expulso da matilha, ele procura o convívio com os homens, mas promete retornar para matar o grande tigre.

Mas o devir-lobo de Mogli lhe impede de viver uma vida pacífica ao lado dos homens. Ele sabe que está na borda das populações humanas, na periferia de seus sentimentos; porém, sente-se ligado a ela por alguma extremidade de seu corpo. Talvez a mão ou o pé. Talvez por uma mãe, que procura há muitos anos, seu filho levado pela floresta e encontrou nos olhos de Mogli, seus pequenos olhos perdidos. Um violento desejo inumano provoca o corpo do menino lobo, ele sabe que se ficar não sobreviverá entre aqueles que fingem seus sentimentos para evitar o conflito desintegrador. Mas a matilha persiste e o acompanha por toda parte. $\mathrm{Na}$ janela, na cidade, nos sonhos. Por vezes o menino vê um grande lobo cinza lhe perseguindo, sedento de sangue e com um filete de baba escorrendo da boca, pronto para devorá-lo ao menor sinal de reação. Mas ele não reage, pois fala todas as línguas e todos os códigos da selva e sabe que o lobo significa um chamado do povo livre para que volte a caçar com a matilha. Tudo isso exige uma grande tensão do menino, mas a sensação de violar as regras é indescritível, quase vertiginosa, quase inumana. Aliás, Mogli entende que não é humano, que o agenciamento casa-homens-cidade funciona apenas para animais gregários e pacíficos, mas não para um membro da matilha. Ele tem mandíbulas de lobo, olhos de lobo, orelhas e pés de lobo, seus dentes caninos são super desenvolvidos para massacrar a carne dos inimigos. Não. Ele não pode aceitar sua humanidade possível. Com a matilha, ele é vários em zonas de intensidade e sua força é muito maior quando aplicada na disputa de territórios de caça.

Seu desejo agora diz: "Sim, eu sou um lobo." Pois toda a vontade e toda a força desse sentir provoca a compreensão instantânea de uma multiplicidade, o preciso instante em que o devir-lobo percorre-lhe as veias para, através de aproximações e distanciamentos, atingir o grau zero da produção desejante. Nesse instante, ele se dissolve de toda a carapaça de valores que aprendera com os homens para tornar-se matilha. É inútil lutar contra vários lobos, pois: "O lobo, os lobos são intensidades, velocidades, temperaturas, distâncias variáveis indecomponíveis. É um formigamento, uma inflamação.” (Deleuze e Guattari, 1995, p.45). Distante dos homens e de seu desejo segmentarizado, aprisionado, encarcerado pelo signo negativo do ressentimento, Mogli pode seguir com a matilha as linhas de fuga, que dão elevado valor positivo aos seus desejos, mesmo os mais obscuros sentimentos são submetidos a essa força centrífuga de produção de alegria. Assim, com a força recobrada, ele volta para a selva a fim de encontrar Shere Khan. 
Agora, com o lobo encarnado, Mogli decide enfrentar o tigre. O grande tigre, o outro de seu próprio medo, o verdadeiro risco da linha de morte e, portanto, da desintegração absoluta.(No sentido edipiano a própria castração, a falta, o inconsciente individual, o instinto de morte, o incesto papai-mamãe-e-eu). Mas ele nunca está sozinho, pois um membro do povo livre nunca anda só e uma matilha é uma multiplicidade molecular que não obedece nenhuma organização hierárquica, nenhuma patologia de ordem inconsciente, porque sabe que o inconsciente é a verdadeira usina de produção do desejo. Não existe medo algum quando os espíritos da selva nos ensinam a extirpar os fantasmas de nossa própria realidade pelo enfrentamento das forças produtivas da natureza contra o devir-reativo de nossa existência. Por isso, Mogli e sua matilha enfrentam e encurralam Shere Khan no meio da mata. O tigre é mais poderoso por sua capacidade de condensar toda a força para o ataque, mas os lobos são exímios estrategistas e conseguem prolongar o ataque para mutilar suas vítimas lentamente. Acuado, o monstruoso tigre se torna um piedoso gatinho domesticado à procura de seu tutor, pois não consegue raciocinar por conta própria, muito menos traçar qualquer estratégia de ataque. A matilha, ao contrário, são multiplicidades selvagens sempre em desacordo, em movimentos de desterritorialização sobre o corpo pleno da terra. O grande caçador da selva é convertido na caça dos lobos e Mogli, agora sem o grande rival, caminha pelas matas ostentando um nobre casaco de pele de tigre.

O devir-lobo de Mogli e Kipling com sua matilha realizam a despersonalização do sujeito autônomo e consciente em proveito de fluxos constantes de devires. Nenhum personagem se sustenta por si próprio, mesmo aqueles que vivem mais isolados como a serpente Ka. O nome próprio e a virtude característica de cada animal aproximam devires humanos dos devires inumanos dos animais. Ao contrário, os devires animais são frequientemente atribuídos a personagens humanas e a cidade nem sempre é melhor lugar para se viver. Quando Mogli foi expulso pelos seus congêneres foi porque os traços inumanos eram visíveis e isso amedrontava, profundamente, as consciências civilizadas. Mogli era a afirmação incondicional dos desejos mais obscuros dos seres humanos, o produto da produção desejante em sua aceitação plena. Não existe, portanto, diferenças de ordem entre os humanos e os animais, mas mecanismos de complementaridade, de exploração intensiva das associações livres, de aproximações e distanciamentos entre o interior e o exterior. Com isso, Freud, com o seu modelo edipiano parece, definitivamente, não concordar. Pois o lobo interior jamais quebrará as grades de sua prisão, ele tem medo do castigo por não obedecer às regras morais da trindade divina. Aliás, onde havia uma matilha, Freud coloca apenas um lobo que, é claro, é o papai, o grande progenitor atravancando a passagem da energia luminosa do inconsciente ( o númen). Porém, de maneira um pouco boçal, poderíamos perguntar: "Cadê a 
mamãe?". Uma criança não brinca apenas de papai e mamãe, porque não existe caráter familiar da sexualidade infantil, mas uma produção coletiva de desejo no interior das máquinas desejantes. Além da energia sexual, a potência não sexual do corpo sem órgãos fornece uma outra leitura do desejo, entendida como força vital e criativa. Talvez a mamãe seja o próprio corpo sem órgãos. E, sobre Freud, resta-nos brindá-lo com a canção do bando Seeonee:

\section{Canção de caça do bando Seeonee}

Quando vinha rompendo a madrugada o cervo bramiu Uma, duas e outra vez mais! E uma corça deu um salto, a corça saltou Do poço onde bebem os veados selvagens.

Isso tudo eu, sozinho, vi acontecer Uma, duas e outra vez mais!

Quando vinha rompendo a madrugada o cervo bramiu

Uma, duas e outra vez mais! E um lobo foi embora, o lobo foi embora Saiu dali para levar a notícia à matilha, que esperava, E todos corremos em seu encalço

Mais uma, duas e outra vez!

Quando rompia a madrugada ouviu-se o uivo da matilha

Uma, duas e outra vez mais! Patas na selva que não deixam marcas! Olhos que enxergam na escuridão- na escuridão! Ouçam a nossa voz! Uma, duas e outra vez mais!

(KIPLING, 1997, p. 36)

\section{Nota bibliográfica}

Rudyard Kipling (1865-1936) nasceu em Bombaim, Índia, e iniciou a carreira profissional como jornalista. Tornou-se um dos mais populares escritores ingleses e era considerado porta voz literário do Império Britânico. A versão que utilizo do livro é uma publicação da L\&PM POCKET, tradução de Vera Karam, 1997.

\section{Referências}

DELEUZE, Gilles; GUATTARI, Félix. O Anti-édipo. Tradução de Georges Lamaziére.

Rio de Janeiro: Imago, 1976.

Mil Platôs: capitalismo e esquizofrenia (Um só ou vários lobos?). Tradução de Aurélia Guerra Neto. Rio de Janeiro: Ed. 34, 1995.

KIPLING, Rudyard. O livro da Selva. Tradução de Vera Karam. Porto Alegre: L\& PM, 1997. 